\title{
Technology Integration in Secondary Physical Education: Teachers' Attitudes and Practice
}

\author{
Anne Gibbone \\ Paul Rukavina \\ Adelphi University \\ Stephen Silverman \\ Columbia University
}

\begin{abstract}
Technology has influenced teaching, yet we know little about physical educators' predispositions and use. This study investigated secondary physical education teachers' attitudes and practices regarding technology integration and relationships between attitude and practice. The data collection instrument measured teachers' attitudes and technology use. Results suggest that teachers had positive attitudes, yet a limited use of technology. Teachers reported a number of barriers influencing technology use including budget, class size, and training. All attitude factors correlated with technology use. Physical educators may be willing to apply technology for teaching if given opportunities to prepare, practice and utilize appropriate resources.
\end{abstract}

Keywords: instructional technology, attitude, physical education

\section{Introduction}

Technology use in schools has influenced the way educators plan, design instruction, and assess their students. Innovations in educational technology have changed systems of communication, learning resources, lesson ideas, and professional development. Innovative technology facilitates creativity and learning productivity. Technology can consist of computer programs, Internet programs, or other assistive, digital and communicative tools. Classroom teachers have integrated these forms of technology over time using a variety of methods through different styles and practices (Becker, 2001; Friedman, 2006; Judson, 2006; Wozney, Venkatesh \& Abrami, 2006).

An area in which technology has not become customary, yet has great potential, is in physical education. Although disciplinespecific technology has been developed, generally, technology inclusion has not become commonplace in physical education due to limitations like lack of training, personal comfort levels, availability of equipment, and space and time (Martin, 2003). Physical educators can integrate technology through a variety of approaches. Preparing, generating, administering, and reporting information such as fitness scores, class participation, or motor skill rubric grades for both students and teachers are completed more efficiently (Posner, 2004). In addition to normal everyday technology use, physical education programs can be structured based on the enhancement of content-specific technology. Physical educators can include the use of word processing and desktop publishing for items like newsletters, information packets or student portfolios. Teachers can 
utilize technology through fitness assessment databases, physical education department Web pages, content-based software programs, multimedia systems and visual presentations. Digital videos, exergaming equipment and other fitness-related devices may be incorporated into daily assignments and unit planning (Mohnsen, 2006). The nature of teaching and the organization of instructional materials can be further developed through the use of the Internet for increased communication, resources, and lesson ideas (Friedman, 2006).

There are a number of factors that contribute to educators' decisions about whether to use technology when planning and teaching. This study focused on four distinct variables pertaining to physical educators; perceptions of relevance and importance of technology; teaching style; technology proficiency; and context. These variables were chosen to be analyzed because of their emergence in reviewed literature. A theoretical framework which designated that these four variables contributed to teachers' attitude about and usage of technology was the basis from which the study was derived. Teachers' individual differences and their environments are considerations along with teachers' attitudes and technology use characteristics. Identification of these variables provides valuable information for those working on curricular modifications, teacher training and professional expectations. As technology becomes increasingly available in schools, the necessity to examine usage, issues of quality and attitude are of greater importance (Dawson \& Ferdig, 2006). Multiple factors contribute to classroom teachers' use of technology and the reasons they integrate it into their professional practice. For example, the way in which teachers perceive relevance or importance of technology in curricula has been shown to predict computer use (Kanaya, Light \& Culp, 2005). Likewise, the value of technology demonstrated by other faculty members influences teachers' technology usage (Albion \& Ertmer, 2002).

The influences on technology use involve both the structures of attitude and practice. The formation of attitudes can provide an understanding of teachers' decisions and perceptions (Lee \& Solmon, 2005). Attitude may serve to explain decisions educators apply to teaching and how they prepare to teach with technology (Lumpe \& Chambers, 2001). Teachers' attitudes and experience are factors associated with computer use (Christensen, 2002; Vannatta \& Fordham, 2004). Both a positive attitude about technology and technology skills in combination are accepted precursors for effective use of technology (Christenson, 2002; Migliorino \& Maiden, 2004). Additional factors that influence attitude are self-efficacy, social norms, and external demands among others.

Along with attitude, quality and quantity of technology training are strong predictors of technology use (Vannatta \& Fordham, 2004). Teachers' technical proficiency and frequency of professional application are significantly associated with computer use, particularly for secondary educators (Becker, 1999). Additional factors that may influence technology use include teaching styles with which the teacher is comfortable and the educational context. Contextual factors can shed light on how teachers interpret their role, respond, and make sense of their work based on their conditions (Lumpe \& Chambers, 2001). Teachers may be constrained by factors such as access to equipment, training, personal comfort levels, availability of equipment, and time. Barriers within a teachers' context may hinder efforts and meaningful use even when the value of technology integration is widely accepted by faculty (Willis, 1993). 
Although distinct attitude and technology use variables have been identified for classroom teachers, variables have not been studied for physical education teachers. It is important to investigate such information because there is no data based information to understand what is necessary for program modification, equipment selection, or effectiveness of technology use. If we better understand attitude of physical education teachers and what influences technology use, this can provide useful information for practitioners, administrators, and teacher preparation programs. Research can be helpful in structuring professional development in physical education through the identification of teachers' concerns and their degree of technology use for both personal preparation and curricular applications. This improvement can translate into better teaching, and in due course impact student achievement.

\section{Method}

\subsection{Instrument Development}

The development of the instrument included several phases which established construct validity. A thorough literature review helped devise a theoretical framework to support underlying factors. The survey was constructed and followed by expert review of content. A pilot study was conducted to address clarity and reliability of scores with secondary level physical education teachers as participants. University professors in physical education, teacher education, and educational technology programs reviewed the survey design and content subsequent to the pilot for further validation of its scores.

The Secondary Physical Educators' Attitudes and Technology Practices Inventory (SPEATPI) was a 36-item online questionnaire developed for this study from a literature review and using previously published instruments (Christensen \& Knezek, 2001; Judson, 2006; Swain, 2006; Wozney et al., 2006). Items were initially clustered into four major factors including (a) physical educators' perceptions of relevance/ importance of technology; (b) physical educators' teaching styles/beliefs; (c) physical educators' technology proficiency and use; and (d) contextual factors. A 5-point Likert-type scale, ranging from strongly agree to strongly disagree was used for the attitude section of the instrument. Other survey items included demographical questions, technology usage, and awareness of technology equipment. The survey was reviewed by twelve professionals for appropriateness of content, design, format, and security to enhance the quality of the Internet questionnaire.

\subsection{Pilot Study}

The pilot study investigated the reliability of the scores from the proposed instrument. The participants in the pilot study were secondary school physical educators' $(N=92)$ who teach one or more classes at the sixth through twelfth grade levels. Survey items were subsequently adjusted based on pilot reliability scores and conceptual fit of items to the theoretical model. After a minor item modification, reliability of scores for each factor in the attitude section of the survey were Physical Educators' Perceptions of Relevance and Importance of Technology $(\alpha=.687)$; Physical Educators' Teaching Style and Beliefs $(\alpha=.733)$; Physical Educators' Technology Proficiency and Use $(\alpha$ $=.757)$; and Contextual Factors $(\alpha=.666)$. The reliability of scores for the use section were; Teachers' Technology Use (Section 1) $(\alpha=$ .974); and Teachers' Technology Use (Section 2) $(a=.837)$. These figures indicate good internal consistency as reliability coefficients of approximately .70 or greater are considered adequate according to social science literature (Hatcher, 1994). 


\subsection{Study}

Following the pilot study, procedures and questionnaire items were evaluated and revised. Data collection procedures and survey components were reviewed to prepare necessary protocols. The SPEATPI survey instrument used for the actual study was prepared with minor modifications to improve clarity of the instrument for participants and the quality of data collection for the researcher. The preparation for subject recruitment involved contacting local, state, and national organizations, including the American Alliance for Health, Physical Education, Recreation, and Dance (AAHPERD), educational institutions, Internet discussion forums and professional Websites, like PE Central, a Website dedicated to providing resources for physical educators. Participants were either contacted via email or were recruited through public communication tools on the Internet. School administrators also were contacted to help facilitate a connection to physical educators by forwarding the survey. Multiple attempts at sending recruitment emails were necessary over the course of data collection.

This study surveyed secondary physical education teachers $(N=616)$ across the United States. Of the 42 states represented, Texas, New York, Florida, Iowa, and Virginia respectively had the most participants. In this sample, 344 (56.4\%) females and 266 (43.6\%) males participated ranging from 22 to 68 years of age $(\bar{x}=42.2$ years, $\mathrm{SD}=10.6)$. Teaching experience ranged from 1 to 50 years $(\bar{x}=15.8$ years, $\mathrm{SD}=10.4$ ) with $98.9 \%$ of the participants having a bachelors degree and $57.0 \%$ attaining a masters degree. Students of these teachers participate in physical education class from 1 to 5 days per week $(\bar{x}=3.7$ days, $\mathrm{SD}=1.4)$ and 25 to 450 minutes within those days ( $\bar{x}$ $=143.4$ minutes, $\mathrm{SD}=99.9)$. The teachers taught in public $(95.7 \%)$, private $(3.6 \%)$, and parochial $(0.7 \%)$ schools. The demographic locations of the schools were suburban (41.8\%), rural $(31.7 \%)$, and urban $(26.5 \%)$. The schools of the teachers participating in the study have populations of 48 to 6200 students ( $\bar{x}=949.9$ students, $\mathrm{SD}=691.2$ ). The average number of students in a physical education class ranged from 4 to 160 students ( $\bar{x}=32.5$ students, SD $=16.2$ ). Teachers reported a range of 0 to 10 classes sharing the same physical education class time period ( $\bar{x}=2.8$ classes, $\mathrm{SD}=1.6$ ).

\subsection{Data Analysis}

All data were exported into statistical software program for analysis. Out of the 616 completed surveys, 94 from the attitude section were dropped because of missing data. Reliability and validity of the survey instrument scores were evaluated by comparing reliability scores with fit indices during the analysis. The alpha coefficient for the entire survey was calculated to be .907 . The entire use section had an alpha coefficient of .940. The alpha coefficients were .961 and .791 , respectively, for use of specific technology and general technology use. The alpha coefficient for the entire attitude section was calculated to be .900. Cronbach's alpha coefficient for interitem reliability was reviewed at several points during data analysis for each factor. Factor analysis was used to establish an attitude instrument score. The promax rotation method for an oblique structure was used and resulted in 30 of the 34 items loading on four factors. The items which loaded on each factor were reviewed for content by comparing the survey questions and deciding the name given to each factor based on common themes. Based on the previous analysis, the placement of some items shifted and some dropped to improve interitem reliability scores and conceptual fit. After working with items and factors to develop the most appropriate fit, the final model consisted of 22 total items separated into four factors. 
Final reliability scores for each factor were: Physical Educators' Perceptions of Importance/ Relevance of Technology $(\alpha=.800)$; Physical Educators' Technology Proficiency $(\alpha=.700)$; Contextual Factors $(\alpha=.670)$; and Physical Educators' Teaching Style $(\alpha=.680)$. These figures, once again, indicate good internal consistency.

Support for construct validity included results from The Goodness of Fit Index (GFI) (.8399), the Adjusted Goodness of Fit Index (AGFI) (.8005), the Root Mean Square Residual (RMSR) (.0729), and the Root Mean Square Error of Approximation (RMSEA) (.0828). The final measurement model was determined by the most parsimonious fit between the fit indices, reliability and theoretical concepts. Content validity was initially assessed prior to the dissemination of the pilot instrument by experts in the field of physical education to ensure that the final factor names and item loadings were consistent with their responses. The slight difference in factor names from the pilot was due to suggestions of experts during this review, which provided a more accurate conceptual model. Content was assessed twice during the actual study, again by professionals in this area. Since items were modified during the process of determining internal reliability and factor analysis, it was important that content validity was retained. The final content assessment resulted in a high percentage of agreement $(\bar{x}$ $=94 \%$ ) by 18 experts. The analyses conducted for descriptive statistics involved reporting the total number of responses and percentages for accessibility, training, and use sections. Total number of responses, percentages, means and standard deviations were reported for the attitude sections. Mean scores for attitude and use factors were used to conduct a two-tailed Pearson correlation analysis. The use section, where individuals selected the frequency of use for 16 technology related tasks, was used for correlation statistics.

\section{Results}

\subsection{Access to Technology}

On average, physical education teachers in this study has one or two computers available in the gymnasium $(\mathrm{SD}=3.9)$. Teachers on average have been provided an office computer and Internet access for the past seven years. Some $91.9 \%$ of educators in this study have Internet access at their home, 90\% have Internet access in their physical education office, and $94.7 \%$ have Internet access in a school computer lab. Approximately half $(48.5 \%)$ of the teachers reported that they have a physical education section on the school district's Website and

Table 1. Contextual Factors Pertaining to Teachers' Technology Use

\begin{tabular}{lrrrrr}
\hline Applicable Barriers & $N$ & $\%$ & Most Challenging Barrier & $N$ & $\%$ \\
\hline Budget & 505 & $81.7 \%$ & Budget & 249 & $40.3 \%$ \\
Class size & 301 & $48.7 \%$ & Class size & 117 & $18.9 \%$ \\
Lack of training & 245 & $39.6 \%$ & Lack of training & 82 & $13.3 \%$ \\
Other & 155 & $25.1 \%$ & Other & 73 & $11.8 \%$ \\
Administrative support & 152 & $24.6 \%$ & Administrative support & 38 & $6.1 \%$ \\
Internet down/unavailable & 110 & $17.8 \%$ & Internet down/unavailable & 19 & $3.1 \%$ \\
Collegial support & 80 & $12.9 \%$ & Collegial support & 18 & $2.9 \%$ \\
\hline
\end{tabular}

Note. Teachers checked all applicable barriers and the barrier perceived to be most challenging 
$17.9 \%$ of those teachers contribute to the Website. Barriers were reported in the survey as they contributed to teachers' considerations about technology use for physical education. The teachers in this study reported budget $(81.7 \%)$ as the most profound barrier, followed by class size $(48.7 \%)$. A list of barriers can be found in Table 1. Interestingly, if barriers were not an issue for educators when using technology for teaching physical education, 561 individuals (90.8\%) agreed they would use technology.

\subsection{Technology Training}

The majority of teachers who participated in this study reported attending approximately 2-3 technology workshops over the past year. Most physical educators reported that they have received professional development session(s) within their district (69.7\%). Additional forms of training reported were self taught skill development (52.1\%), training from colleagues/peers (38.7\%), college/university coursework (34.6\%), and professional development sessions outside of their district $(31.4 \%)$. Only $7.8 \%$ of teachers did not have any formal training. Of those who had training, the highest responses to the specific type of training received involved basic computer literacy $(78.8 \%)$ and basic computer applications (77.5\%). Less than half of the sample, had training in advanced computer applications (46\%) and computer training for curricula integration (36.6\%). More than half of these teachers reported receiving either a full day (35.9) or multiple full/half days over a number of years $(28 \%)$. Only $5.8 \%$ of teachers attended a full semester course in technology.

\subsection{Technology Use}

In this study, over $90 \%$ of teachers use a computer for personal and professional work, the Internet and email, and the computer while at work on a daily basis. Approximately $78 \%$ use a computer daily at home. When calculating the number of educators who give assignments that require technology use, serve on technology committees, or review/select technology products, 70\% or more occasionally or never do those things. About $60 \%$ of teachers occasionally or never use a computer during instruction in physical education, discuss technology/ Internet with other teachers, or help others use computers/technology. Around $48 \%$ of physical educators in this study occasionally or never use any technology to teach physical education content. Over $75 \%$, however, use a computer either weekly or daily for lesson preparation. More than half of these teachers use the Internet to acquire teaching resources and rely on technology for daily preparation or routine tasks at a weekly minimum.

Teachers were asked to report their perceived level of technology use in one or more areas using a progressive scale from 1 (little knowledge of technology use) to 9 (I apply technology throughout my curriculum). The percentage of teachers who self assessed their level of application of technology to be at the most extensive level was $30.1 \%$. The majority, however, rank themselves toward the middle of the continuum where they believe that they use technology intermittently and for short-term or specified tasks only. At these levels teachers are aligned with being fairly comfortable with technology use and are still in a preparation phase for more comprehensive technology integration. Teachers were asked to report their knowledge, accessibility, confidence, and technology use for teaching pertaining to specific technology items. The results indicate that the most known and accessed piece of technology for teachers in this study is their school website. Teachers indicated that they feel most confident 
using their email and reported the most used technology equipment to teach with as computer word processing. A list of clustered technology items by type and average percentages for technology use are reported in Table 2.

Table 2. Average Percentages for Technology Use Variables based on Clustering of Technology Items by Type

\begin{tabular}{lccccc}
\hline & Knowledge & Accessibility & Confidence & $\begin{array}{l}\text { Use for } \\
\text { teaching }\end{array}$ & Non-Use \\
\hline Internet Related Tools & $45.6 \%$ & $29.2 \%$ & $37.2 \%$ & $20.5 \%$ & $31 \%$ \\
$\begin{array}{l}\text { General Computer } \\
\text { Software }\end{array}$ & $48.1 \%$ & $23.8 \%$ & $35.1 \%$ & $31.1 \%$ & $27.8 \%$ \\
$\begin{array}{l}\text { General Computer } \\
\text { Hardware }\end{array}$ & $49.1 \%$ & $28.2 \%$ & $31.6 \%$ & $20.6 \%$ & $34.8 \%$ \\
$\begin{array}{l}\text { PE Specific Computer } \\
\text { Software }\end{array}$ & $47.3 \%$ & $18.7 \%$ & $23.9 \%$ & $21.1 \%$ & $41.7 \%$ \\
$\begin{array}{l}\text { PE Specific Hardware } \\
\text { Sart }\end{array}$ & $50 \%$ & $18.4 \%$ & $30.6 \%$ & $26.5 \%$ & $32 \%$ \\
\hline
\end{tabular}

Note. Multiple responses were acceptable within the five categories for each item

\subsection{Attitude}

Teachers in this study generally had positive attitudes about technology use for teaching physical education. The overall means for the factors revealed the common responses to items were favorable, indicating teachers had a positive attitude. Means for each factor were reported using a scale of 1(strongly agree) to5 (strongly disagree) for responses and are presented in Table 3. Approximately 95\% of teachers who participated in this survey indicated that technology can enhance the quality of physical education. Around $90 \%$ of the teachers have increased their use of the Internet and the computer over the past three years and would like to learn about and use technology more. Educators in this study indicated (82\%) that they would consider technology when redesigning curriculum and 57\% responded to making an effort to apply technology in their current curriculum. Respondents revealed (76\%) technology training as a positive experience and $82 \%$ attempt to implement new technology once they learn it. Based on these figures, it is not surprising that the majority of teachers $(92 \%)$ in this study expressed that they use a variety of learning methods for students in physical education class. Of the physical educators who participated, just 34\% indicated that technology is frustrating to use without help and $70 \%$ feel confident with their current abilities. Teachers expressed (80\%) that using technology to teach is enjoyable for them, yet (53\%) responded that technical problems and troubleshooting make them feel tense. 
Table 3. Means and Standard Deviations for Attitude Items

\begin{tabular}{|c|c|c|c|c|}
\hline Factors & & $N$ & Mean & $\mathrm{SD}$ \\
\hline \multirow{4}{*}{$\begin{array}{c}\text { Perception of } \\
\text { Importance/ } \\
\text { Relevance }\end{array}$} & Technology can enhance the quality of PE & 609 & 1.52 & 0.67 \\
\hline & I use a variety of learning methods for students in physical education. & 609 & 1.79 & 0.74 \\
\hline & Having more technology available would increase my use when teaching. & 605 & 2.04 & 0.91 \\
\hline & After learning something about technology, I attempt to implement it. & 606 & 2.11 & 0.77 \\
\hline \multirow{4}{*}{$\begin{array}{c}\text { Mean }=2.05 \\
\mathrm{SD}=0.37\end{array}$} & Technology training has been a positive experience for me. & 604 & 2.21 & 0.92 \\
\hline & I would consider technology when redesigning my curriculum. & 606 & 2.05 & 0.79 \\
\hline & I make an effort to apply a variety of technology within my instruction. & 600 & 2.60 & 1.06 \\
\hline & I feel confident with my current ability to use technology for teaching. & 608 & 2.32 & 1.07 \\
\hline $\begin{array}{l}\text { Technology } \\
\text { Proficiency }\end{array}$ & Most technology is frustrating to use for me without help. & 605 & 2.44 & 1.11 \\
\hline \multirow{2}{*}{$\begin{array}{l}\text { Mean }=2.46 \\
\mathrm{SD}=0.54\end{array}$} & Technical problems or troubleshooting makes me feel tense. & 603 & 3.19 & 1.14 \\
\hline & Using technology to teach is enjoyable for me. & 608 & 1.90 & 0.90 \\
\hline \multirow{6}{*}{$\begin{array}{l}\text { Contextual } \\
\text { Factors } \\
\text { Mean }=2.69 \\
\mathrm{SD}=0.61\end{array}$} & I am expected to be knowledgeable in uses of technology. & 607 & 2.02 & 0.91 \\
\hline & In my school, most teachers use technology when teaching. & 602 & 2.24 & 0.98 \\
\hline & I know of many PE teachers who use technology to teach. & 608 & 2.82 & 1.10 \\
\hline & I have enough technology equipment appropriate for my class size. & 606 & 3.79 & 1.17 \\
\hline & I can easily access technology resource personnel in my school. & 607 & 2.61 & 1.19 \\
\hline & $\begin{array}{l}\text { My suggestions for staff development activities are valued by } \\
\text { administrators. }\end{array}$ & 604 & 2.67 & 1.04 \\
\hline \multirow{5}{*}{$\begin{array}{c}\text { Teaching Style } \\
\begin{array}{c}\text { Mean }=2.48 \\
\mathrm{SD}=0.47\end{array}\end{array}$} & Technology takes time away from more important concerns. & 605 & 2.49 & 1.03 \\
\hline & Technology does not accommodate personal learning styles. & 606 & 2.21 & 0.88 \\
\hline & It is difficult using technology to teach PE. & 605 & 2.68 & 1.13 \\
\hline & Behavior management effects my decision to use technology in PE. & 600 & 3.07 & 1.13 \\
\hline & Technology use promotes student motivation/participation in PE class. & 610 & 1.93 & 0.89 \\
\hline
\end{tabular}

This factor reported the lowest attitude of the four attitude factors based mean scores. The mean score $(2.69, \mathrm{SD}=0.61)$, however, still indicates that teachers generally responded positively to these items. Teachers indicated $(69 \%)$ that most teachers in their school use technology for teaching. Only $41 \%$, however, know of many physical educators who use technology to teach. Some $80 \%$ of the teachers believe they are expected to be knowledgeable in uses of technology. As far as having enough equipment to accommodate class size, only $29 \%$ of teachers indicated they do. Approximately $60 \%$ of teachers can easily access technology 
resource personnel in their school. Some $62 \%$ of physical educators from this study have many barriers that limit their use of technology.

Physical education teachers indicated (77\%) that using technology in class promotes student motivation or participation. Around $38 \%$ of teachers believe that technology takes time away from more important concerns. Just $27 \%$ responded that technology does not accommodate personal learning styles. Only $31 \%$ of teachers find it difficult for them to use technology to teach physical education, but $45 \%$ think that behavior management affects their decision to use technology.

\subsection{Relationships among Attitudes and Technology Use}

When examining the five factors, four for attitude and one for use, significant Pearson Product Moment correlations were found between all of the factors. Some relationships, however, were stronger than others. The results indicate that a strong relationship exists between teachers' perceptions of relevance/ importance of technology and their technology use $(r(510)=.565, p<.01)$. The factors of teachers' perceptions of relevance/importance of technology and teachers' technology proficiency were also positively correlated $(r$ $(510)=.549, p<.01)$. A positive correlation was found between teachers' perceptions of relevance/importance of technology and physical educators' teaching style $(r(510)=$ $.536, p<.01)$. A strong relationship also exists between teachers' technology proficiency and their technology use $(r(510)=.516, p<.01)$.

\section{Discussion}

\subsection{Instrument Development}

The theoretical framework used to guide this study includes teachers' attitudes and practices about technology use for teaching. Teachers' attitudes and technology use are divided into interdependent sub-factors of physical educators' perceptions of relevance/ importance of technology, physical educators' teaching style, contextual factors, and physical educators' technology proficiency. The values for internal consistency for attitude were acceptable, however, a larger sample size would ideally provide improved reliability scores (Cronbach, 1951). It was determined that for descriptive items, reliability and content validity were important to produce a strong instrument to measure these items. Scores from factor analysis determined an acceptable fit of the data with the theoretical model (Thomas, Nelson \& Silverman, 2005). The survey was subject to revisions throughout the process to establish instrument validity and reliability scores. Decisions on re-specifying were based on statistical outcomes in alignment with theory and content assessment (Anderson $\&$ Gerbing, 1988) and multiple reviews from experts in the field. Checking reliability scores at multiple points during re-specification allowed for considerations to items that might have otherwise been overlooked. Taking extra steps to review and appropriately modify survey items or theoretical definitions provided stronger results to further support study findings.

\subsection{Teachers' Attitudes and Technology Use}

Results indicated that participants tended to be experienced teachers who frequently use the computer and Internet for general purposes. Attitude has been associated with both teaching experience and years of computer experience (Friedman, 2006; Iding, Crosby \& Speitel, 2002). Positive attitudes toward technology use are linked with the amount of technology experience an individual attains (Migliorino \& Maiden, 2004). It is not surprising that 
the participants in this study demonstrate characteristics that directly relate to attitude outcomes. Positive attitudes and experience, however, do not necessarily translate into technology use. Participants perceived a high expectation to use technology, yet expectations may not be realistic if teachers are faced with implementation challenges. Identified challenges like budget, class size, and lack of training certainly inhibit use of technology to teach physical education. Multiple barriers seem to pose integration difficulties for teachers based on the results of this study and other studies have reported similar findings with teachers in other fields (Brzycki \& Dudt, 2005; Franklin, 2007; Friedman, 2006).

Concerns about budget translate into the ability to purchase desirable equipment and software appropriate for teachers' and/ or students' use. The amount of equipment a teacher requires that is appropriate for maximal student learning parallels their class size. The average number of computers located in a gymnasium $(N=1.5)$ does not allow for technology integration using computer programs. Accessibility of other hardware in school was low and reasonably affected the low percentage of use for teaching. Barriers reported in the literature were consistent with those reported by teachers in this study (Friedman, 2006; Park \& Ertmer, 2008), which found that teachers find budget concerns as most problematic, and this led to limited equipment and/or resources. Constraints on use certainly affect the extent to which teachers can use technology for teaching, regardless of their attitude. Due to the cessation of use by barriers, it may be wise for universities and school districts to advise both candidates and practitioners in methods to combat costs and devise alternative means to increase their technology accessibility and/or functionality.
Class size does not seem to be a limiting factor in technology use according this study $(\bar{x}=32.5$ students, $\mathrm{SD}=16.2$, median $=30)$, yet class size was the second most challenging barrier reported by participants in this study for not using technology. The reported class size is a manageable number of students, so teachers concern may be due to their perception of the amount of technology equipment needed for their students as opposed to the amount of students in their class. Inequity in resources or financial support between disciplines can be a cause of concern. When issues of preference are noted, however, this raises concern about the value of the subject matter. It is not a surprise that participants reported their feelings of disparity among disciplines as physical education has been faced with marginalization issues (Lee \& Solmon, 2005). If physical education programs have low status among other content areas, budget decisions and priority of funding will be directed toward other areas that are viewed with more recognition or as being more important (Martin, 2003). The low status of physical education has been studied in past research (Silverman \& Ennis, 2003) and can result in a lack of resources, professional development, equipment and support.

Results from this study additionally do not show a strong indication that teachers know of other physical educators who use technology for teaching. Teachers typically interact most with physical educators in the same school or district, so they also are likely to have limited resources. This can influence the use of technology by the participant as use by other physical educators can have a direct effect on an individual's views and behaviors (Albion $\&$ Ertmer, 2002). Teachers using technology does not mean that they use it in a positive or productive manner. More exposure, however, could be a beneficial subsidiary. Interestingly, teachers reported knowing of 
other teachers outside of physical education who use technology to a much greater degree. Technology use in physical education is being accepted at a generally slow rate, so it is practical to investigate the reasons why this is the case (Martin, 2003).

\subsection{Technology Training}

Technology training was predominantly a positive experience for teachers and although the quality of the training was not examined, teachers were likely to hold a positive attitude about technology when their training experiences were positive. Quality training encourages meaningful use (Christensen, 2002). A large number of participants attended workshops within their district, but the content of the workshops is unknown. It can be meaningful to investigate the quality and focus of these training sessions in order to understand the nature of teacher's interactions with technology applications. A number of participants reported self taught skills, which likely requires a great deal of practice time. Teachers who have high computer skills tend to spend twice as much time working on computers in school as other teachers (Becker, 2000). It is clear from the literature that if the expectation is for teachers to use technology, it is critical to start technology training during pre-service fieldwork (Mulholland, 2006). Teachers who take a course in technology applications during pre-service teacher education are more likely to have a positive attitude (Bai \& Ertmer, 2008) and a third of the sample in the study participated in such a college course.

\subsection{Technology Use}

Teachers who participated in this study have an overall positive attitude about technology use, so it is likely that low levels of direct use for teaching students can be attributed to contextual factors, and not negative attitude or low skill proficiency. The results of this study clearly demonstrated that if teachers with positive attitudes have more access to technology, it is likely they will use it for teaching. If teachers with poor attitudes have access to technology, it is unlikely they will use technology for teaching because an educators' decision typically reflects their own feelings over simply having the equipment availability (Hernández-Ramos, 2005; Johnson \& Howell, 2005). The amount of technology use can depend on an individual's purpose and the equipment that is available (Drucker, 2006). The most frequently used items are computers, email and the Internet, so it is likely that most teachers are using these items for personal use or teaching preparation and not for instruction.

Modeling by other physical educators did not seem to be occurring for teachers in this study, so lack of peer support may have had an effect on low technology usage in schools. The attendance at technology workshops for the participants in this study also did not dictate technology use by physical educators for teaching, class assignments or homework. Attending workshops does not guarantee that technology taught to educators will be used for teaching or student assignments (Brzycki \& Dudt, 2005).

\subsection{Teachers'Attitudes}

Overwhelmingly, participants acknowledged a willingness to use technology for teaching. This is in line with previous studies that have shown perceived value and relevancy of technology use for instruction effects teachers' use (Becker, 1999; Park \& Ertmer, 2008). Teachers who typically have a more student-centered philosophy tend to use technology, given that resources are provided (Becker, 2001). In this study, these teachers tended to have a greater inclination to use technology. Other research has demonstrated 
that the main requirement for technology integration is for teachers to have a philosophy of adapting their instructional strategies to differing needs of their class and students (Levin \& Wadmany, 2006). Fundamentally, teachers' beliefs have a tendency to influence teaching practices (Pajares, 1992).

\subsection{Relationships between Use and Attitude}

There was a positive relationship between the factors of technology use and teachers' attitudes about technology as correlations were found between these factors. Among the factors for attitude and technology use, the strongest correlations were found between technology use and teachers' perception of importance/ relevance of technology and between technology proficiency and teachers' perception of importance/relevance of technology. Positive attitudes about technology training tend to lead to technology use. Increased use encourages improved technical proficiency (Vannatta \& Fordham, 2004). Positive attitudes about the value of technology can be related to the amount of training an individual participates in and increased use as both attitude and proficiency have positively correlated with amounts of training or coursework (Johnson \& Howell, 2005). Less than $10 \%$ of the participants had no formal training, therefore, the correlation made sense based on the data. Although these correlations were significant, the strength of the relationships between these variables should be considered. The total $r^{2}$ for these relationships was .301 and .319 respectively. Based on the size of this sample, the correlations (approximately .550) in this study can provide substantial insight about relationships.

The results from this study, therefore, indicate that involvement in technology training and higher levels of computer skill competency was associated with positive attitudes about technology use for teachers who used computers for personal use (Becker, 1999; Christensen \& Knezek, 2001; Iding et al., 2002; Wozney et al., 2006). In this study, almost $92 \%$ of teachers reported using a computer for personal use and about $78 \%$ use a computer at home, so previous research would support that teachers in this sample are likely competent in their computer skills.

The priority of technology within educational curricula depends on teachers' decisions about the degree of applicability of technology (Baur \& Kenton, 2005). Teachers' application of technology is effective when they are interested in the development of technology integration within curricula (Goddard, 2002). Teachers in this sample clearly have an interest in using technology to teach physical education. In order for curriculum and teaching to be influenced by technology, it will take more than teachers' interest. Being interested in the topic, however, does not seem to be a challenge to overcome for these individuals. As general technology use increases, most teachers become interested in learning about instructional uses of technology because they recognize its value (Iding et al., 2002). Teachers' perceptions of relevance or importance of technology in curricula have been shown to predict computer use (Kanaya, Light \& Culp, 2005). It was not unexpected, therefore, that the overall positive attitude of this sample extended into an inclination to consider technology during curriculum changes.

It is important to understand what teachers think in order to develop teacher training, curriculum plans, and teaching tools. If it is deemed desirable for physical educators to integrate technology in their teaching, analysis of teachers' feelings and contextual factors influencing use is a necessary foundation. Teachers in this study expressed positive attitudes even though their reported 
technology use was not prominent. It is promising that physical educators similar to those who participated in this study are likely willing to learn and apply technology if given the opportunity to prepare themselves and if supplied with appropriate resources. Although these educators are confident about their skills and perceive technology use to be important, increased usage of technology for teaching physical education is not likely unless implementation barriers are removed. These findings are very much supported by other literature as is likely that most teachers will be challenged with barriers when attempting or continuing to integrate technology. Some barriers that involve equipment or training limitations, generally considered as first-order, may have less complicated solutions than those that are considered second-order, for example, personal beliefs or rigid curricula formats. The main concern is that teachers who are prepared to face these barriers are more likely to overcome them through strategic planning (Ertmer, 1999).

This study provided strong data to understand what middle and high school physical educators think about technology use and how they are currently using technology through a reliable and valid instrument designed from the theoretical framework. The findings from this study are similar to past research in other areas of education, however, physical education has discipline specific challenges. These challenges make it necessary to pursue this initial investigation with physical education as a unique context. This study has added to the body of research regarding conditions for technology integration and provided further knowledge of attitude components and current practices pertaining to physical educators' views and teaching practices.

\section{References}

Albion, P.R., \& Ertmer, P.A. (2002). Beyond the foundations: The role of vision and belief in teachers' preparation for integration of technology. TechTrends, 46, 34-38.

Anderson, J.C., \& Gerbing, D.W. (1988). Structural equation modeling in practice: A review and recommended two-step approach. Psychological Bulletin, 103, 411423.

Bai, H., \& Ertmer, P.A. (2008). Teacher educators' beliefs and technology uses as predictors of preservice teachers beliefs and technology attitudes. Journal of Technology and Teacher Education, 16, 93-112.

Bauer, J., \& Kenton, J. (2005). Toward technology integration in the schools: Why it isn't happening. Journal of Technology and Teacher Education, 13, 519-546.

Becker, H. J. (1999, February). Internet use by teachers. (Teaching, Learning, and Computing-1998 National Survey, Report \#1). Center for Research on Information Technology and Organizations, University of California, Irvine. Retrieved June 20, 2006 from http://www.crito.uci.edu/TLC/ FINDINGS/internetuse/

Becker, H. J. (2000, June). Findings from the Teaching, Learning, and Computing Survey: Is Larry Cuban right? Revision of a paper presented at the January, 2000 School Leadership Conference of the Council of Chief State School Officers, Washington, D.C. Retrieved October 29, 2006 from http://www.crito.uci.edu/tlc/html/findings. html

Becker, H.J. (2001). How are teachers using computers in instruction? Retrieved December 1, 2006 from http://www.crito.uci. edu/tlc/html/conference-presentations.html

Brzycki, D. \& Dudt, K. (2005). Overcoming barriers to technology use in teacher preparation programs. Journal of Technology and Teacher Education, 13, 619-641. 
Christensen, R. (2002). Effects of technology integration education on the attitudes of teachers and students. Journal of Research on Technology in Education, 34, 411-433.

Christensen, R., \& Knezek, G. (2001). Instruments for Assessing the Impact of Technology in Education. In Assessment/ Evaluation in Educational Information Technology. Computers in the Schools, $18(2 / 3), 5-25$.

Cronbach, L. J. (1951). Coefficient alpha and the internal structure of tests. Psychometrika, 16, 297-334.

Dawson, K., \& Ferdig, R. E. (2006). Commentary: Expanding notions of acceptable research evidence in educational technology: A Response to Schrum et al. Contemporary Issues in Technology and Teacher Education, 6(1), 133-142.

Drucker, M. J. (2006). Commentary: Crossing the digital divide: How race, class, and culture matter. Contemporary Issues in Technology and Teacher Education, 6(1), 43-45.

Ertmer, P. (1999). Addressing first- and second-order barriers to change: Strategies for technology integration. Educational Technology, Research and Development, 47(4), 47-62.

Franklin, C. (2007). Factors that influence elementary teachers' use of computers. Journal of Technology and Teacher Education, 15, 267-293.

Friedman, A. (2006). K-12 teachers' use of course websites. Journal of Technology and Teacher Education, 14, 795-810.

Goddard, M. (2002). What do we do with these computers? Reflections on technology in the classroom. Journal of Research on Technology in Education, 35, 19-26.

Granello, D. H. \& Wheaton, J.E. (2004). Online data collection: Strategies for research. Journal of Counseling and Development, 82, 387-394.
Hatcher, L. (1994). A step by step approach to using the SAS system for factor analysis and structural equation modeling. Cary, NC: SAS Institute.

Hernández-Ramos, P. (2005). If not here, where? Understanding teachers' use of technology in Silicon Valley schools. Journal of Research on Technology in Education, 38, 39-64.

Iding, M., Crosby, M. E., \& Speitel, T. (2002). Teachers and technology: Beliefs and practices. International Journal of Instructional Media, 29, 153-170.

Johnson, G. M., \& Howell, A. J. (2005). Attitude toward instructional technology following required versus optional WebCT usage. Journal of Technology and Teacher Education, 13, 643-654.

Judson, E. (2006). How teachers integrate technology and their beliefs about learning: Is there a connection? Journal of Technology and Teacher Education, 14, 581-597.

Kanaya, T., Light, D., \& Culp, K. M. (2005). Factors influencing outcomes from a technology-focused professional development program. Journal of Research on Technology in Education, 37, 313-329.

Lee, A.M., \& Solmon, M.A. (2005). Pedagogy research through the years in RQES. Research Quarterly for Exercise and Sport, 76, 108-121.

Levin, T. \& Wadmany, R. (2006). Teachers' beliefs and practices in technology-based classrooms: A developmental view. Journal of Research on Technology in Education, 39, 157-182.

Lumpe,A. T., \& Chambers, E. (2001). Assessing teachers' context beliefs about technology use. Journal of Research on Technology in Education, 34, 93-107.

Martin, L.T. (2003). Context of schools. In S.J. Silverman \& C.D. Ennis (Eds.), Student learning in physical education: Applying research to enhance instruction ( $2^{\text {nd }}$ ed., $\mathrm{pp}$. 43-62). Champaign, IL: Human Kinetics. 
Migliorino, N. J., \& Maiden, J. (2004). Educator attitudes toward electronic grading software. Journal of Research on Technology in Education, 36, 193-212.

Mohnsen, B. (2006). Using technology in physical education. Cerritos, CA: Bonnie's Fitware.

Mulholland, R. (2006). A technology snapshot: Teacher preparation program and the local public schools. Contemporary Issues in Technology and Teacher Education, 6, 284292.

Pajares, F. (1992). Teachers' beliefs and educational research: Cleaning up a messy construct. Review of Educational Research, 62, 307-332.

Park, S.H., \& Ertmer, P.A. (2008). Impact of problem-based learning on teachers' beliefs regarding technology. Journal of Research on Technology in Education, 40, 247.

Posner, G., (2004). Analyzing the curriculum. ( $3^{\text {rd }}$ ed.). New York: McGraw-Hill.

Silverman, S.J. \& Ennis, C.D. (2003). Student learning in physical education: applying research to enhance instruction. Champaign, IL: Human Kinetics.

Thomas, J., Nelson, J., \& Silverman, S. (2005). Research methods in physical activity. Champaign, IL: Human Kinetics.

Vannatta, R. A., \& Fordham, N. (2004). Teacher dispositions as predictors of classroom technology use. Journal of Research on Technology in Education, 36, 253-271.

Willis, J. (1993). What conditions encourage technology use? It depends on the context. Computers in the Schools, 9(4), 13-32.

Wozney, L., Venkatesh, V., \& Abrami, P.C. (2006). Implementing computer technologies: Teachers' perceptions and practices. Journal of Technology and Teacher Education, 14, 173-207. 


\section{Contact the Authors}

Anne Gibbone, Ed.D.

Adelphi University, USA

E-mail: gibbone@adelphi.edu

Paul Rukavina, Ph.D.

Adelphi University, USA

E-mail: rukavina@adelphi.edu

Stephen Silverman, Ed.D.

Columbia University, USA

E-mail: silverman@exchange.tc.columbia.edu 